\title{
Arterial Microcalcifications in the Breast Mimicking Malignancy
}

\author{
Katrin Janzen ${ }^{1}$ and Jan Janzen ${ }^{2}$ \\ ${ }^{1}$ Praxis für Gynäkologie und Geburtshilfe, Bollwerk 35, 3011 Berne, Switzerland \\ ${ }^{2}$ Praxis für Histopathologie, Postfach 350, 3000 Berne 22, Switzerland \\ Correspondence should be addressed to Katrin Janzen, janzen@hin.ch \\ Received 5 October 2011; Accepted 2 November 2011 \\ Academic Editor: P. K. Vanhoenacker
}

Copyright ( $\odot 2012$ K. Janzen and J. Janzen. This is an open access article distributed under the Creative Commons Attribution License, which permits unrestricted use, distribution, and reproduction in any medium, provided the original work is properly cited.

Microcalcifications in the breast are highly suggestive of malignancy; they can occur in many pathological conditions. A 36-yearsold nondiabetic woman came to the gynaecologist with a suspect palpable mass in the upper outer quadrant of the right breast. Histopathological examination confirmed a calcification of a small artery (diameter: $0.45 \mathrm{~mm}$ ). Arterial calcifications can mimic a malignant lesion in the breast.

\section{Introduction}

Vascular calcifications as a form of crystallization are reflecting a complex biological mechanism. Calcifications can occur in many pathological conditions, for instance, in toxic injuries and in long-term treatment with corticosteroids. Furthermore, cell death in apoptosis and mitochondrial vesicles can be responsible for calcifications. Recent studies are focusing on the inhibition effect of Matrix-Gla protein [1].

\section{Case Presentation}

A 36-years-old nondiabetic woman came to the gynaecologist with a suspect palpable mass $(1.5 \mathrm{~cm}$ in diameter $)$ in the upper outer quadrant of the right breast. Radiologically, unclear groups of microcalcifications were detected in the mammogram (Figure 1). Three stereotactic 11-gauge vacuum-assisted breast biopsies were performed. Microscopically, fragmented breast biopsies with a total length of $6.0 \mathrm{~cm}$ were examined. Typical aspects of lobular hyperplasia characterised by enlarged and hypercellular lobules were found. In the adjacent stroma rare mononuclear inflammatory infiltrates and small fibrotic foci were localised. Furthermore a small muscular-type artery with circumferentially arranged smooth muscle cells in the tunica media was removed.
Intimal and adventitial layers of the artery showed no pathological changes. However, in the tunica media amorphous deposits - stained blue and violet in hematoxylin-eosinwere observed. These microcalcifications had a diameter of $0.45 \mathrm{~mm}$.

Our case showed typical aspects of calcifications in a muscular type artery, where calcifications develop alongside the internal elastic membrane [2]. Microcalcifications were removed by biopsies in toto. There were no signs of malignancy. Arterial calcifications frequently occur in elderly people (senile medial calcinosis, Moenckeberg's medial sclerosis) [3]. Diabetes mellitus and hyperlipidaemia have been reported with high prevalence in young and middle-aged woman with breast arterial calcifications [4].

It is well known that microcalcifications in the breast are highly suggestive of malignancy. Uncertain calcifications should indicate a further histopathological examination to confirm their biological behaviour [5-7]. So, benign microcalcifications associated with apocrine metaplasia in fibrocystic breast disease and after breastfeeding were diagnosed $[8,9]$.

\section{Conclusion}

Arterial calcifications are pathologic and can mimic a malignant lesion in the breast. 


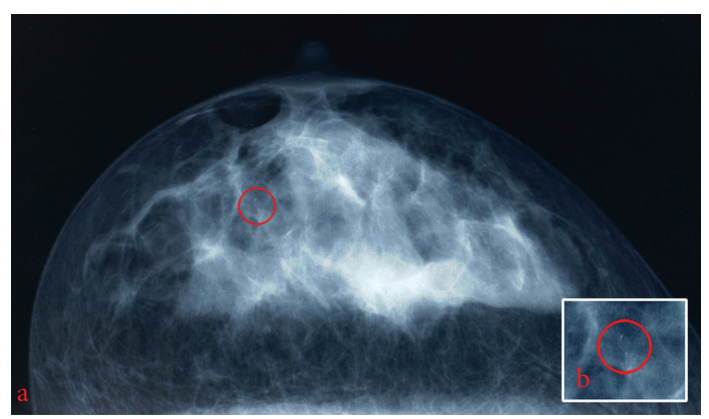

FIGURE 1: Radiologic aspects presenting small microcalcifications $(\mathrm{a}, \mathrm{b})$.

\section{Consent}

Written consent was obtained from the patient for publication of the case report and any accompanying images.

\section{Conflict of Interests}

The authors declare that they have no competing interests.

\section{Authors' Contribution}

K. Janzen performed the surgery and was in charge of patient care. J. Janzen carried out the histopathological examination.

\section{References}

[1] L. J. Schurgers, H. Aebert, C. Vermeer, B. Bültmann, and J. Janzen, "Oral anticoagulant treatment: friend or foe in cardiovascular disease?” Blood, vol. 104, no. 10, pp. 3231-3232, 2004.

[2] J. Janzen, B. Bultmann, M. Leitritz, K. Rothenberger-Janzen, and P. N. Vuong, "Histopathological aspects of arterial calcifications," Perfusion, vol. 16, pp. 136-140, 2003.

[3] B. B. Nielsen and N. V. Holm, "Calcification in breast arteries. The frequency and severity of arterial calcification in female breast tissue without malignant changes," Acta Pathologica Microbiologica et Immunologica Scandinavica, Section A, vol. 93, no. 1, pp. 13-16, 1985.

[4] M. Moskowitz and M. Verani, "Monckeberg's arteriosclerosis revisited: or silver vessels among the old," Canadian Association of Radiologists Journal, vol. 27, no. 3, pp. 200-202, 1976.

[5] C. Hirst and N. Davis, "Core biopsy for microcalcifications in the breast," Australian and New Zealand Journal of Surgery, vol. 67, no. 6, pp. 320-324, 1997.

[6] L. Liberman, C. A. Gougoutas, M. F. Zakowski et al., "Calcifications highly suggestive of malignancy: comparison of breast biopsy methods," American Journal of Roentgenology, vol. 177, no. 1, pp. 165-172, 2001.

[7] A. Fischmann, B. Pietsch-Breitfeld, M. Müller-Schimpfle et al., "Radiologic-histopathologic correlation of microcalcifications from 11G vacuum biopsy: analysis of 3196 core biopsies," Röfo Fortschr Geb Röntgenstr Neuen Bildgeb Verfahr, vol. 176, no. 4, pp. 538-543, 2004.

[8] J. Janzen, A. Fischmann, and K. Rothenberger-Janzen, "Microcalcifications in association with apocrine metaplasia in fibrocystic breast disease," Singapore Journal of Obstetrics and Gynaecology, vol. 33, pp. 47-49, 2002.
[9] G. L. Giron, S. K. Boolbol, J. Gross, J. M. Cohen, and S. Feldman, "Postlactational microcalcifications," Breast Journal, vol. 10, no. 3, pp. 247-252, 2004. 


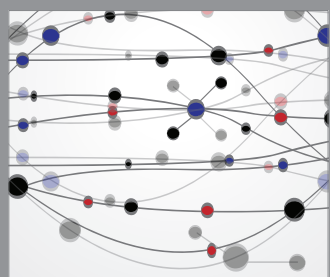

The Scientific World Journal
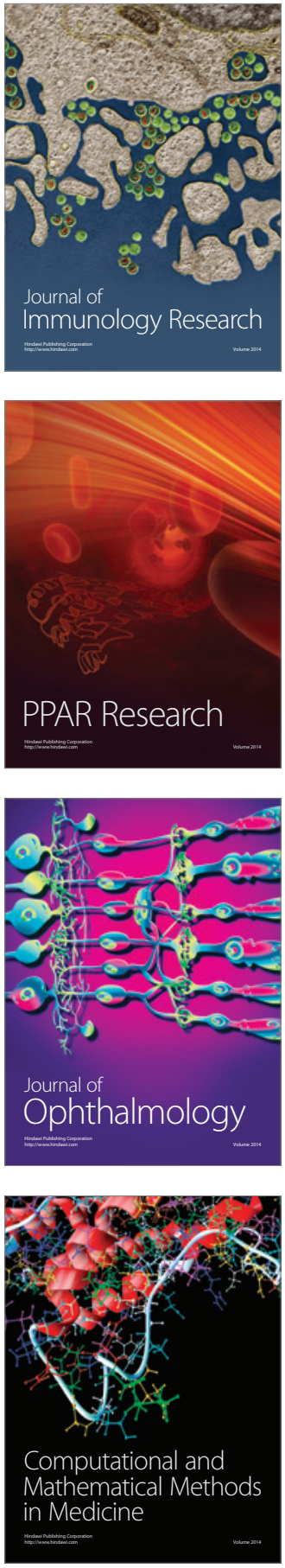

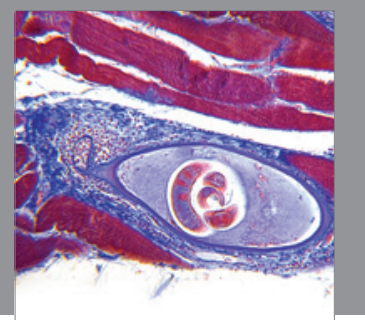

Gastroenterology

Research and Practice
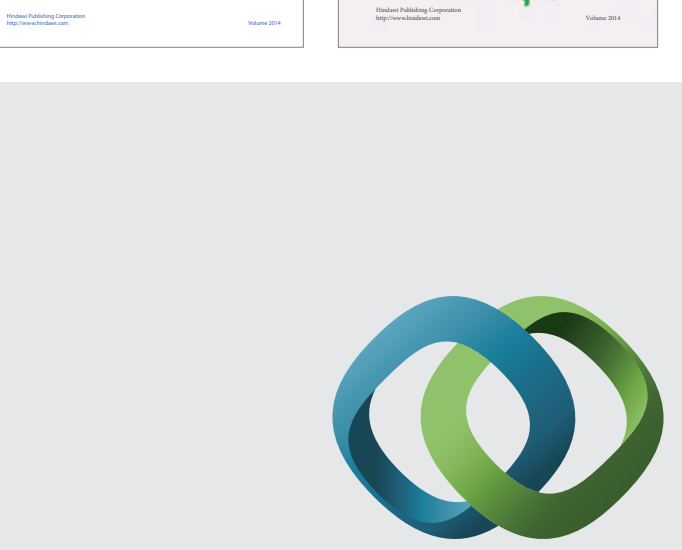

\section{Hindawi}

Submit your manuscripts at

http://www.hindawi.com
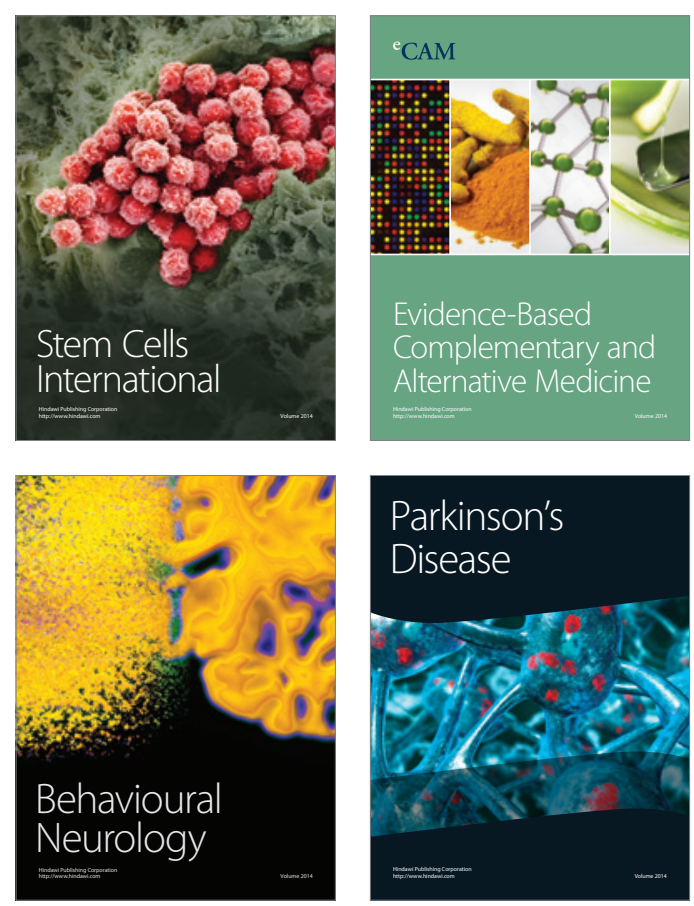

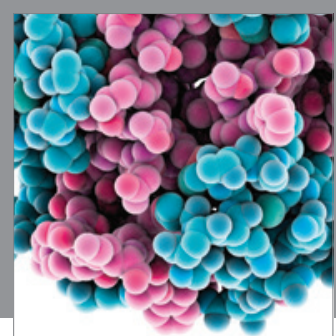

Journal of
Diabetes Research

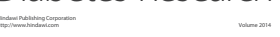

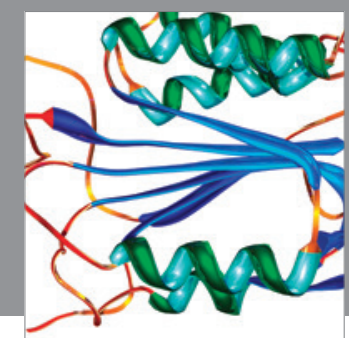

Disease Markers
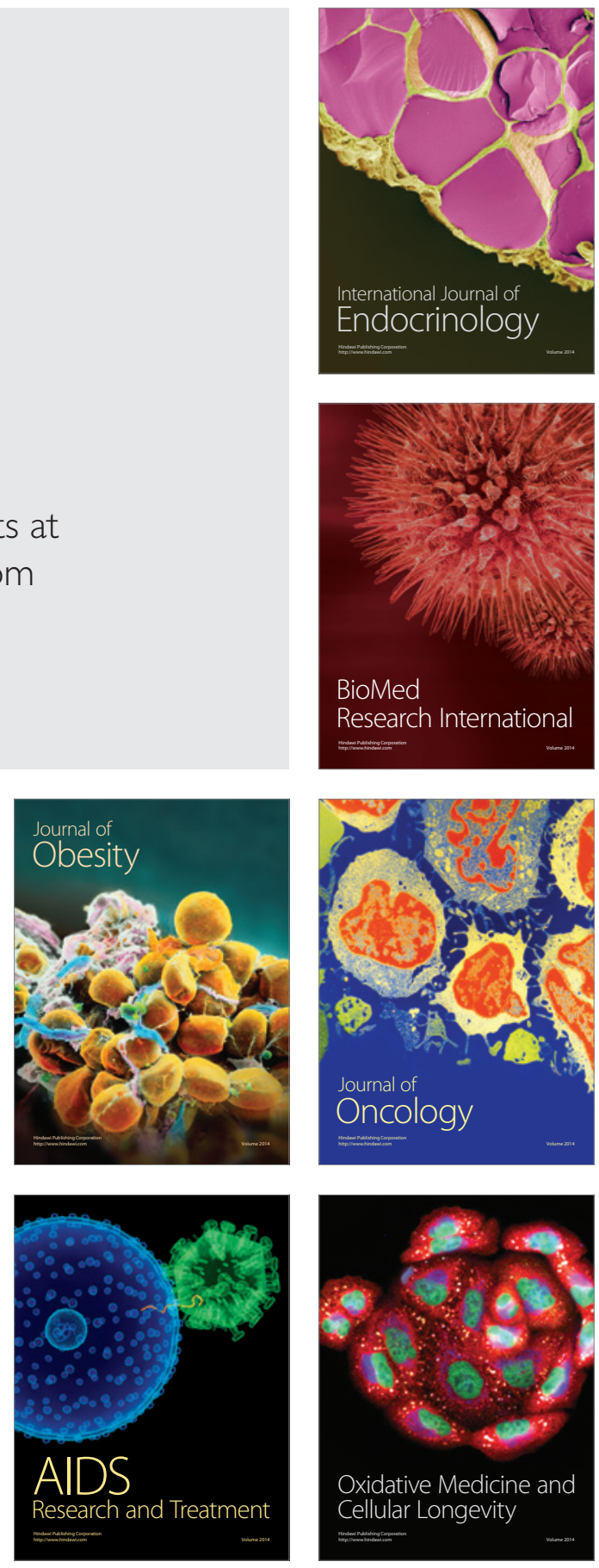